\title{
Removal of natural organic matter by titanium tetrachloride: the effect of total hardness and ionic strength
}

\author{
Y.X. Zhao ${ }^{\mathrm{a}}$, H.K. Shon ${ }^{\mathrm{b}}$, S. Phuntsho ${ }^{\mathrm{b}}$, B.Y. Gao ${ }^{\mathrm{a}}$ * \\ ${ }^{a}$ Shandong Key Laboratory of Water Pollution Control and Resource Reuse, School \\ of Environmental Science and Engineering, Shandong University, No. 27 Shanda \\ South Road, Jinan, 250100, People’s Republic of China \\ ${ }^{\mathrm{b}}$ Centre for Technology in Water and Wastewater, School of Civil and Environmental \\ Engineering, University of Technology, Sydney (UTS), P.O. Box 123, Broadway, \\ NSW 2007, Australia
}

\begin{abstract}
This study is the first attempt to investigate the effect of total hardness and ionic strength on coagulation performance and the floc characteristics of titanium tetrachloride $\left(\mathrm{TiCl}_{4}\right)$. Membrane fouling under different total hardness and ionic strength conditions was also evaluated during a coagulation-ultrafiltration (C-UF) hybrid process. Coagulation experiments were performed with two simulated waters, using humic acid (HA, high molecular weight) and fulvic acid (FA, relatively low molecular weight), respectively, as model natural organic matter (NOM). Results show that both particle and organic matter removal can be enhanced by increasing total hardness and ionic strength. Floc characteristics were significantly influenced by total hardness and ionic strength and were improved in terms of floc size, growth rate, strength, recoverability and compactness. The results of the UF tests show that the pre-coagulation with $\mathrm{TiCl}_{4}$ significantly improves the membrane permeate fluxes. Under different total hardness and ionic strength conditions, the membrane permeate flux varied according to both NOM and floc characteristics. The increase in total hardness and ionic strength improved the membrane permeate flux in the case of HA simulated water treatment.
\end{abstract}

Keywords: Coagulation-flocculation; Titanium tetrachloride; Total hardness; Ionic strength; Membrane fouling

${ }^{*}$ Corresponding author. Tel.: +86 531 88366771; fax: +86 53188364513

E- mail address: baoyugao_sdu@aliyun.com (B. Y. Gao) 


\section{Introduction}

Natural organic matter (NOM) is a diverse mixture of organic compounds with different molecular weights, such as humic acid (HA) with high molecular weight and fulvic acid (FA) with relatively low molecular weight (Kabsch-Korbutowicz 2005). The NOM causes odor, taste, color, and bacterial re-growth in potable water, and has the potential to form carcinogenic disinfection-byproducts (DBPs) (Hu et al. 2006). Thus, the effective removal of NOM has become increasingly important in modern water treating systems. Coagulation and flocculation have been the most common methods of removing NOM and large particles in water treatment processes (Jarvis et al. 2005).

Aluminum (Al) and iron (Fe) salts are widely used as effective coagulants in removing a broad range of impurities, including colloidal particles and organic substances (Duan and Gregory 2003). However, the production of large amounts of sludge requiring further disposal is the main drawback of using conventional $\mathrm{Al}$ and Fe coagulants. The sludge post-treatment is considered to be one of the most costly and environmentally problematic challenges of all water treatment works (Kane 1987, Nassar et al. 2009). Recently, titanium tetrachloride $\left(\mathrm{TiCl}_{4}\right)$ has been investigated as an alternative coagulant because its efficiency is comparable to, or higher than, both $\mathrm{Al}$ and Fe salts (Zhao et al. 2011a, Zhao et al. 2011b). Additionally, the $\mathrm{TiCl}_{4}$ coagulant produces floc of larger size and higher growth rate than conventional coagulants, resulting in better settleability. The most significant advantage is that the $\mathrm{TiCl}_{4}$ flocculated sludge can be recycled to produce valuable byproduct by calcination (Zhao et al. 2011a, Shon et al. 2009, Shon et al. 2007, Lee et al. 2009, Okour et al. 2010), namely titanium dioxide $\left(\mathrm{TiO}_{2}\right)$, which is the most widely used metal oxide and whose applications include photocatalysts, cosmetics, paints, electronic paper, and solar cells (Hoffmann et al. 1995, Obee and Brown 1995). Therefore, utilizing $\mathrm{TiCl}_{4}$ as a coagulant combines comparable or superior coagulation efficiency and sludge disposal.

Floc characteristics are key influences in the solid/liquid separation process and affect coagulation efficiency (Yu et al. 2009). Smaller particles settle more slowly than larger particles of similar density (Boller and Blaser 1998). Thus, small particles generally have lower removal efficiency by coagulation-flocculation than larger particles. The ability of flocs to withstand rupture and recoverability after they are broken has a significant impact at water treatment works (WTW), since the unit processes at WTW have prevalent regions of high shear (McCurdy et al. 2004). Floc strength and recoverability are therefore considered to be important parameters in understanding coagulation behaviour. Floc fractal dimension $\left(\mathrm{D}_{f}\right)$ is another particularly important operational parameter influencing the solid/liquid separation process (Gregory 1998).

Both coagulation performance and floc characteristics depend not only on characteristics of the water source and coagulants, and hydraulic parameters (shear 
force and break-up period), but also on various water quality parameters, such as solution $\mathrm{pH}$, total hardness and ionic strength. (Hu et al. 2006, Yukselen and Gregory 2004). Although much attention has been paid to the effect of coagulant dose, solution $\mathrm{pH}$ and hydraulic conditions on coagulation efficiency and floc characteristics by $\mathrm{TiCl}_{4}$ (Zhao et al. 2011a, Zhao et al. 2011b, Zhao et al. 2011c, Zhao et al. 2011d), there is no available report on the effect of total hardness and ionic strength on coagulation performance and floc properties by $\mathrm{TiCl}_{4}$.

Ultrafiltration (UF) technology has been extensively investigated as an effective water treatment process for the removal of suspended solids, colloidal material $(>0.1 \mu \mathrm{m})$, NOM and DBPs precursors (Jucker and Clark 1994, Zularisam et al. 2006). However, serious membrane fouling necessitated the employment of coagulation pre-treatment prior to UF to improve NOM removal and reduce membrane fouling (Guigui et al. 2002, Park et al. 2002, Oh 2005). Nonetheless, there is no available literature concerning the effect of total hardness and ionic strength on membrane fouling using $\mathrm{TiCl}_{4}$ as a coagulant during the coagulation-ultrafiltration (C-UF) hybrid process.

The overall objectives of this paper are to: i) investigate the effect of total hardness and ionic strength on coagulation performance by $\mathrm{TiCl}_{4}$ for both $\mathrm{HA}$ and FA removal; ii) assess the influence of total hardness and ionic strength on floc properties, including floc growth rate, size, strength, recoverability and structure; iii) examine membrane fouling during the C-UF process under different total hardness and ionic strength conditions. To our best knowledge, this is the first attempt to elucidate the effect of total hardness and ionic strength on the coagulation behaviour of $\mathrm{TiCl}_{4}$. Since $\mathrm{TiCl}_{4}$ has only recently been investigated as a coagulant, this study helps to acquire a better understanding of the correlation of the coagulation performance of $\mathrm{TiCl}_{4}$ with the characteristics of raw water.

\section{Experimental}

\subsection{Coagulant and test water}

$\mathrm{TiCl}_{4}$ stock solution $(20 \%$, density $=1.150 \mathrm{~g} / \mathrm{ml})$ was obtained from Photo \& Environment Technology Co. Ltd. (South Korea).

HA and FA simulated water samples were used in this study. The HA stock solution $(1.0 \mathrm{~g} / \mathrm{L})$ was prepared as follows: $1.0 \mathrm{~g}$ of HA (supplied by Ju-Feng Chemical Technology Co., Ltd, Shanghai, China), together with 0.04 g sodium hydroxide $(\mathrm{NaOH})$, was dissolved in deionized water under continuous stir for $30 \mathrm{~min}$, and the solution was then diluted to $1.0 \mathrm{~L}$. $\mathrm{NaOH}$ was used to promote the dissolve of HA. The stock solution of FA $(1.0 \mathrm{~g} / \mathrm{L})$ was prepared by dissolving $1.0 \mathrm{~g}$ of FA (biochemical reagent, purchased from Yinong Biochemical Technology Co. Ltd., Shanghai, China) directly in deionized water. 
Coagulation experiments were performed with two simulated water samples: i) containing $10 \mathrm{mg} / \mathrm{L}$ of HA prepared in deionized water and tap water (Yang et al. 2010), in which the turbidity, $\mathrm{UV}_{254}$ absorbance, dissolved organic carbon (DOC), zeta potential and $\mathrm{pH}$ of the suspension was $3.59 \pm 0.02 \mathrm{NTU}, 0.432 \pm 0.005 \mathrm{~cm}^{-1}$, $4.096 \pm 0.144 \mathrm{mg} / \mathrm{L},-14.5 \pm 0.5 \mathrm{mV}$ and 8.2-8.4, respectively; ii) containing $10 \mathrm{mg} / \mathrm{L}$ of FA prepared in tap water (Wang et al. 2012), in which the turbidity, $\mathrm{UV}_{278}$ absorbance, DOC, zeta potential and $\mathrm{pH}$ of the suspension was $0.45 \pm 0.02 \mathrm{NTU}, 0.089 \pm 0.002 \mathrm{~cm}^{-1}$, $4.905 \pm 0.145 \mathrm{mg} / \mathrm{L},-15.0 \pm 1.0 \mathrm{mV}$ and 8.3-8.4, respectively.

\subsection{Jar-test}

Standard jar tests were conducted using a programmable jar-tester (ZR4-6, Zhongrun Water Industry Technology Development Co. Ltd., China). The water sample (1000 $\mathrm{mL}$ ) was mixed rapidly for $30 \mathrm{~s}$ at $200 \mathrm{rpm}$ before coagulant was added. After addition of the coagulant, rapid mixing (200 rpm) was performed for 1 min followed by slow mixing at $40 \mathrm{rpm}$ for a duration of $15 \mathrm{~min}$, which was then followed by 15 min of quiescent settling. Water samples were collected from $2 \mathrm{~cm}$ below the water surface for measurements. The water samples were pre-filtered using a $0.45 \mu \mathrm{m}$ fibre membrane syringe filter before testing $U_{254}$ or $U_{278}$ (absorbance at $254 \mathrm{~nm}$ or 278 nm using a UV-754 UV/VIS spectrophotometer), while turbidity was directly measured without filtration using a 2100P turbidimeter (Hach, USA).

Coagulation-flocculation experiments under different total hardness conditions were conducted after the total hardness of the test water was adjusted to different levels by $\mathrm{CaCl}_{2}$ solids. The ionic strength of the test water was adjusted from $0.05 \mathrm{~mol} / \mathrm{L}$ to 0.4 $\mathrm{mol} / \mathrm{L}$ by $\mathrm{NaCl}$ solid before the coagulation test.

\subsection{Floc characterization}

A laser diffraction instrument (Mastersizer 2000, Malvern, UK) was used to measure dynamic floc size as the coagulation and flocculation process proceeded. The schematic diagram of the on-line monitoring system for dynamic floc size can be found in Zhao et al. (2011b). The median equivalent diameter, $d_{50}$, was selected as the representative floc size, although the same trends were observed for $d_{10}$ and $d_{90}$ floc sizes. The floc growth rate was calculated by the slope of the rapid growth region (Xiao et al. 2010):

Growth rate $=\frac{\Delta \text { size }}{\Delta \text { time }}$

Following the floc growth phase, the aggregated flocs were exposed to a shear force at $200 \mathrm{rpm}$ for $5 \mathrm{~min}$, followed by a slow mixing at $40 \mathrm{rpm}$ for $15 \mathrm{~min}$ to allow floc regrowth, with the aim of studying the floc breakage and recovery properties. Floc strength factor $\left(\mathrm{S}_{f}\right)$ and recovery factor $\left(\mathrm{R}_{f}\right)$ are used to compare floc breakage and recoverability (Jarvis et al. 2005, Zhao et al. 2011b, Cao et al. 2011, Zhao et al. 2012): 
Strength factor $\left(\mathrm{S}_{f}\right)=\frac{d_{2}}{d_{1}} \times 100$

Recovery factor $\left(\mathrm{R}_{f}\right)=\frac{d_{3}-d_{2}}{d_{1}-d_{2}} \times 100$

where, $d_{1}$ is the average floc size of the plateau before breakage, $d_{2}$ is the floc size after the floc break-up period, and $\mathrm{d}_{3}$ is the floc size after regrowth to the new plateau. The higher the $S_{f}$ value, the less sensitive the flocs are to breakage. Likewise, the floc with a larger $\mathrm{R}_{f}$ shows better recoverability after being subjected to high shear force.

Previous researches have reported the determination of aggregate mass fractal dimension $\left(\mathrm{D}_{f}\right)$ using Mastersizer 2000 (Jarvis et al. 2005, Lin et al. 2008, Wei et al. 2009). The total scattered light intensity $I$, the scattering vector $Q$, and $D_{f}$ follows the power law below (Rieker et al. 2000):

$I \propto Q^{-D f}$

The scattering vector $Q$ is the difference between the incident and the scattered wave vectors of the radiation beam in the medium (Lin et al. 2008):

$Q=\frac{4 \pi n \sin (\theta / 2)}{\lambda}$

where, $n, \lambda$ and $\theta$ are the refractive index of the medium, the laser light wavelength in vacuum, and the scattering angle, respectively. Densely packed aggregate has a higher $\mathrm{D}_{f}$ value, while a lower $\mathrm{D}_{f}$ value results from a large, high branched and loose bound structure.

\subsection{Coagulation-ultrafiltration (C-UF)}

A UF membrane with a molecular weight cut-off (MWCO) of $100 \mathrm{kDa}$ was provided by Mosu Shanghai. All the UF experiments were carried out using a magnetically stirred cell (MSC050, Mosu, China), with a total holding capacity of $300 \mathrm{~mL}$ and an effective membrane area of $50.2 \mathrm{~cm}^{2}$. The cell was pressurized with nitrogen gas at $0.15 \pm 0.05 \mathrm{MPa}$ without shaking. An electronic balance (MSU5201S-000-D0, Sartorius AG Germany) connected to a PC was employed to measure the mass of the UF permeate. The mass data was recorded every $10 \mathrm{~s}$ and the flux decline with time was calculated to assess membrane fouling. Schematic diagrams of the experiment of the C-UF hybrid process can be found in Xu et al. (2011). 


\section{Results and discussion}

\subsection{Coagulation performance}

Initially, standard jar tests were conducted to separately assess the effect of total hardness and ionic strength on the coagulation efficiency of $\mathrm{TiCl}_{4}$ for both simulated HA and FA water treatments. Usually, water can be classified into several categories (Wang et al. 2010): very soft water (total hardness $<89 \mathrm{mg} / \mathrm{L}$ as $\mathrm{CaCO}_{3}$ ), soft water (90 mg/L as $\mathrm{CaCO}_{3}<$ total hardness $<159 \mathrm{mg} / \mathrm{L}$ as $\mathrm{CaCO}_{3}$ ), medium hard water (160 $\mathrm{mg} / \mathrm{L}$ as $\mathrm{CaCO}_{3}<$ total hardness $<229 \mathrm{mg} / \mathrm{L}$ as $\mathrm{CaCO}_{3}$ ), fairly hard water (230 mg/L as $\mathrm{CaCO}_{3}<$ total hardness $<339 \mathrm{mg} / \mathrm{L}$ as $\mathrm{CaCO}_{3}$ ), hard water $(340 \mathrm{mg} / \mathrm{L}$ as $\mathrm{CaCO}_{3}<$ total hardness $<534 \mathrm{mg} / \mathrm{L}$ as $\mathrm{CaCO}_{3}$ ) and very hard water (total hardness $>$ $535 \mathrm{mg} / \mathrm{L}$ as $\mathrm{CaCO}_{3}$ ). In this study, the total hardness range was selected from 40 to $200 \mathrm{mg} / \mathrm{L}$ as $\mathrm{CaCO}_{3}$, since both HA and FA exist in very soft water, soft water and medium soft water (Wang et al. 2010). The ionic strength was chosen at a wide range from 0.05 to $0.4 \mathrm{~mol} / \mathrm{L}$.

\subsubsection{The effect of total hardness on coagulation efficiency}

Fig. 1 presents the influence of total hardness on residual turbidity, $\mathrm{UV}_{254}$ or $\mathrm{UV}_{278}$ removal and floc zeta potential for both HA and FA simulated water treatment. Two coagulant doses were selected for each of the HA and FA simulated water treatments. In the case of the HA simulated water treatment, the residual turbidity decreased with increasing total hardness, which was accompanied by the increase in $\mathrm{UV}_{254}$ removal. The decrease in residual turbidity and increase in $U_{254}$ removal was inconspicuous at total hardness $>80 \mathrm{mg} / \mathrm{L}$. The variation in residual turbidity and $U_{278}$ removal vs. total hardness during FA simulated water treatment (Fig. 1 (b)) showed a similar trend to that seen during the HA simulated water treatment. The difference is that the $\mathrm{UV}_{278}$ removal with $30 \mathrm{mg} / \mathrm{L}$ of $\mathrm{TiCl}_{4}$ was independent of total hardness within the total hardness range investigated, with $\mathrm{UV}_{278}$ removal of around $67.0 \pm 0.5 \%$.

Fig. 1 The effect of total hardness on coagulation performance for simulated HA (a) and FA (b) water treatment

Changes in floc zeta potential as a function of total hardness are also presented in Fig. 1 , with the results suggesting that the floc zeta potential gradually increased with the increase in total hardness regardless of the coagulant dose for both the HA and FA simulated water treatment. This indicates that $\mathrm{CaCl}_{2}$ may bind with the $\mathrm{HA} / \mathrm{FA}$ molecule, altering the surface characteristics of HA/FA and changing its removal efficiency. The negative charges on HA/FA molecules surfaces are speculated to have decreased as a result of binding $\mathrm{Ca}^{2+}$ with positive charge, which may facilitate the reaction between $\mathrm{HA} / \mathrm{FA}$ and the hydrolyzates of $\mathrm{TiCl}_{4}$. Moreover, the metal reacts with organic contaminants (Tuncay et al. 1994) and the binding of metal with organic matter has been proved to improve organic removal efficiency (Hankins et al. 2006). Therefore, the increasing total hardness led to an increase in HA and FA removal 
efficiency, as shown in Fig. 1. The effect of total hardness on HA and FA removal varied with coagulant dose. At a low $\mathrm{TiCl}_{4}$ dose, $\mathrm{Ti}(\mathrm{OH})^{3+}, \mathrm{Ti}(\mathrm{OH})_{2}{ }^{2+}$, and $\mathrm{Ti}(\mathrm{OH})_{3}{ }^{+}$ might be the dominant hydrolyzates of $\mathrm{TiCl}_{4}$ (XU et al. 2009), while at higher doses, the coagulant conditions became more favourable for hydroxide precipitation. The monomer Ti species reacts with HA/FA to form HA/FA-Ti(OH) ${ }_{\mathrm{x}}{ }^{(4-\mathrm{x})+}$ complexes, which change to Ca-HA/FA-Ti(OH) $)_{\mathrm{x}}{ }^{(4-x){ }^{+}}$complexes with $\mathrm{Ca}^{2+}$ addition. With an increasing $\mathrm{TiCl}_{4}$ dose, large polymer Ti species may aggregate and remove $\mathrm{HA}$ and FA by patch coagulation. The small variation in $U^{254}$ removal and $U V_{278}$ removal as a function of total hardness at high $\mathrm{TiCl}_{4}$ doses indicates that the coagulation efficiency of the monomer Ti species is influenced more by total hardness than by the efficiency of large polymer Ti species.

\subsubsection{The effect of ionic strength on coagulation efficiency}

Fig. 2 presents the effect of ionic strength on both HA and FA removal in terms of residual turbidity and $\mathrm{UV}_{254}$ or $\mathrm{UV}_{278}$ removal. The $\mathrm{TiCl}_{4}$ dose was chosen at $10 \mathrm{mg} / \mathrm{L}$ and $20 \mathrm{mg} / \mathrm{L}$, respectively for HA and FA simulated water treatments. Irrespective of the type of water treatment, the increase in ionic strength significantly decreased the residual turbidity and improved both $U_{254}$ and $U V_{278}$ removal, which indicates that the reaction between the hydrolyzates of $\mathrm{TiCl}_{4}$ and $\mathrm{HA}$ or $\mathrm{FA}$ are enhanced by increasing the ionic strength of the water. In the case of the HA simulated water treatment, the residual turbidity decreased from around 3.5 NTU to about 1.5 NTU when the ionic strength of raw water increased to $0.1 \mathrm{~mol} / \mathrm{L}$, whereas the lowest residual turbidity of approximately 1.4 NTU was obtained in the FA simulated water treatment. The $\mathrm{UV}_{254}$ removal and $\mathrm{UV}_{278}$ removal increased from $80.0 \%$ and $48.3 \%$ to $90.0 \%$ and $56.7 \%$, respectively, with an ionic strength of $0.1 \mathrm{~mol} / \mathrm{L}$. However, as the ionic strength was increased, a minimal increase in $\mathrm{UV}_{254}$ and $\mathrm{UV}_{278}$ removal was noted, while the residual turbidity was higher than with an ionic strength of $0.1 \mathrm{~mol} / \mathrm{L}$. Therefore, it can be concluded that the inorganic ions with certain concentration in natural water improve the coagulation performance with $\mathrm{TiCl}_{4}$.

Fig. 2 The effect of ionic strength on coagulation performance for simulated HA (a) and FA (b) water treatment

The variation of floc zeta potential vs. ionic strength showed the inverted parabolic trend illustrated in Fig. 2 in both the HA and FA simulated water treatments. The floc zeta potential decreased to the lowest value (around $-26.3 \mathrm{mV}$ and $-21.4 \mathrm{mV}$, respectively for HA and FA simulated water treatment) at the ionic strength of 0.1 $\mathrm{mol} / \mathrm{L}$, followed by a gradually increasing trend as the ionic strength increased. The floc zeta potentials were all negative within the ionic strength range investigated, indicating the predominant coagulation mechanism of sweep flocculation. The increasing ionic strength facilitated the residual turbidity and HA/FA removal, as reflected by the improvement in turbidity and organic matter removal. It can be speculated that the increase in ionic strength may be ascribed to the compressed 
electric double layer, which made the sweep flocculation convenient. After coagulation, the zeta potential of the microflocs in the supernatant varied with different ionic strength values. With the increasing ionic strength, the decrease in floc zeta potential indicated that the resultant coagulated suspension was more and more stable. However, further increases in the ionic strength resulted in the gradual increase of zeta potential. This corresponds well with the report that metal ion activity decreases with increasing ionic strength (S.J. Xu 2002). This could also explain the negligible increase in $\mathrm{UV}_{254}$ or $\mathrm{UV}_{278}$ removal at high ionic strength.

\subsection{Floc characterization}

The effect of total hardness and ionic strength on floc characteristics formed by $\mathrm{TiCl}_{4}$ was investigated for both HA and FA simulated water treatments. The size of the flocs during kinetic floc growth, breakage and regrowth processes was monitored on-line using Mastersizer 2000 and the flocs were characterized in terms of growth rate, size, strength, recoverability and fractal dimension.

\subsubsection{The effect of total hardness on floc characteristics}

The floc growth, breakage and regrowth profiles at different total hardness levels for both HA and FA simulated water treatments are presented in Fig. 3. Floc characteristics during floc growth, breakage and regrowth processes were significantly affected by total hardness, which is evident from the variation in floc growth rate and size (Fig. 4), and floc $S_{f}, R_{f}$ and $D_{f}$ (Table 1) under different total hardness conditions.

Fig. 3 The kinetic floc growth, breakage and regrowth profiles under different total hardness conditions for simulated HA (a) and FA (b) water treatment

Fig. 4 Variation of floc growth rate and floc size $d_{1}, d_{2}$ and $d_{3}$ vs. total hardness for simulated HA (a) and FA (b) water treatment

Table 1 The effect of total hardness on floc $S_{f}, R_{f}$ and $D_{f}$ for both HA and FA simulated water treatment

In the case of HA simulated water treatment (Fig. 4(a)), floc growth rate and floc size $\mathrm{d}_{1}, \mathrm{~d}_{2}$ and $\mathrm{d}_{3}$ increased with increasing total hardness. However, a total hardness that is too high may cause deterioration in floc properties, which is evident from the decrease in both floc growth rate and size at total hardness of $200 \mathrm{mg} / \mathrm{L} \mathrm{CaCO}_{3}$ with $\mathrm{TiCl}_{4}$ dose of $5 \mathrm{mg} / \mathrm{L}$. The presence of carboxylate and phenolate groups gives the humic acid the ability to form complexes with $\mathrm{Ca}^{2+}$. Many humic acids have two or more of these groups arranged so as to enable the formation of chelate complexes (Tipping, 1994). The repulsion between $\mathrm{TiCl}_{4}$ hydrolyzates and $\mathrm{HA}$ molecules was reduced by $\mathrm{Ca}^{2+}$ addition, since negative charges of HA molecules may be reduced by 
$\mathrm{Ca}^{2+}$. Thus, the increase in total hardness may facilitate the reaction between $\mathrm{TiCl}_{4}$ hydrolyzates and HA molecules, which therefore results in the increase in floc size and floc growth rate with increasing total hardness. The decrease in floc growth rate and size at the total hardness of $200 \mathrm{mg} / \mathrm{L} \mathrm{CaCO}_{3}$ with $\mathrm{TiCl}_{4}$ dose of $5 \mathrm{mg} / \mathrm{L}$ might be caused by the particle repulsion due to the overdose of $\mathrm{Ca}^{2+}$. By contrast, the effect of total hardness on floc growth rate and size was barely observed in the case of the FA simulated water treatment (Fig. 4(b)). There is little variation in floc size and growth rate with increasing total hardness, regardless of the $\mathrm{TiCl}_{4}$ dose used. FA has smaller size with lower molecular weight than that of humic acids, with molecular weights ranging from approximately 1500 or less (Senesi, 1990). Though FA is of low molecular weight, it is capable of complexing or chelating 2 to 6 times more $\mathrm{Ca}^{2+}$ than other higher molecular weight complexing agents, i.e. HA (Hoffmann et al., 1981). All of the $\mathrm{Ca}^{2+}$ is expected to dissolve and become mobilized fulvic complexes, therefore, both floc size and growth rate were barely influenced by the concentration of $\mathrm{Ca}^{2+}$.

The variation of floc $\mathrm{S}_{f}, \mathrm{R}_{f}$ and $\mathrm{D}_{f}$ with total hardness for both HA and FA simulated water treatments is presented in Table 1 . With the increasing coagulant concentration, the coagulation conditions are expected to be more favourable for hydroxide precipitation and the coagulation mechanism transforms from charge neutralization to sweep flocculation (Zhao et al., 2012). This may be the main reason why the flocs formed by $\mathrm{TiCl}_{4}$ at lower coagulant doses had higher $\mathrm{R}_{f}$ than those at higher doses within the total hardness range investigated, regardless of HA and FA simulated water treatment. Since the flocs formed by charge neutralization can fully recover, while the flocs formed by sweep flocculation are irreversible after breakage (Yu et al., 2009). For HA simulated water treatment, the increase in total hardness resulted in a decrease in both $\mathrm{S}_{f}$ and $\mathrm{R}_{f}$ in the case of a $\mathrm{TiCl}_{4}$ dose of $5 \mathrm{mg} / \mathrm{L}$, while in the case of a $\mathrm{TiCl}_{4}$ dose of $10 \mathrm{mg} / \mathrm{L}$, both $\mathrm{S}_{f}$ and $\mathrm{R}_{f}$ first decreased and then increased with increasing total hardness. This indicates that coagulant dose plays an important role in the influence of total hardness on floc properties. For the FA simulated water treatment, $\mathrm{S}_{f}$ showed minimal variation (from around $35.2 \%$ to $41.6 \%$ ) with total hardness, which indicates that the FA molecules bond $\mathrm{Ca}^{2+}$ into their molecular structure and the $\mathrm{Ca}^{2+}$ barely influences the floc $\mathrm{S}_{f}$. However, after floc breakage, the $\mathrm{Ca}^{2+}$ addition favours the re-aggregation of floc fragments, resulting in the increase in floc $\mathrm{R}_{f}$ within the low total hardness range. The decrease in $\mathrm{R}_{f}$ under high total hardness conditions might be attributed to the particle repulsion between floc fragments due to the adherence of $\mathrm{Ca}^{2+}$ on floc surface after breakage. The $\mathrm{R}_{f}$ increased from about $43.2 \%$ to $54.5 \%$ at a total hardness of $80 \mathrm{mg} / \mathrm{L} \mathrm{CaCO}_{3}$, but decreased to $34.6 \%$ at a total hardness of $100 \mathrm{mg} / \mathrm{L} \mathrm{CaCO}_{3}$.

The increase in total hardness also improved floc compactness to different degrees before floc breakage, as reflected by the increase in $\mathrm{D}_{f}$. After floc breakage, the floc fragments were expected to rearrange at more favourable points (Hopkins and Ducoste 2003, Selomulya et al. 2001), resulting in a substantial increase in $\mathrm{D}_{f}$. The $\mathrm{D}_{f}$ after floc breakage and regrowth was comparable, and was increased or decreased to 
varying extent depending on the total hardness. For instance, in the case of FA removal at the coagulant dose of $20 \mathrm{mg} / \mathrm{L}$, the $\mathrm{D}_{f}$ after breakage increased from 2.74 to 2.78 at total hardness of $40 \mathrm{mg} / \mathrm{L} \mathrm{CaCO}_{3}$, but decreased to 2.69 at total hardness of $150 \mathrm{mg} / \mathrm{L} \mathrm{CaCO}_{3}$.

\subsubsection{The effect of ionic strength on floc characteristics}

The response of the kinetic floc growth, breakage and regrowth profiles with different ionic strength conditions varied significantly, as shown in Fig. 5. The floc growth rate and size under different ionic strength conditions are presented in Fig. 6. Results suggest that, for HA simulated water treatment, both floc size and growth rate show an increasing trend with increasing ionic strength. For FA simulated water treatment, floc growth rate shows little variation within the ionic strength range investigated, while the floc size shows increasing trend with the increase in ionic strength.

Fig. 5 The kinetic floc growth, breakage and regrowth profiles under different ionic strength conditions for simulated HA (a) and FA (b) water treatment

Fig. 6 Variation of floc growth rate and floc size $d_{1}, d_{2}$ and $d_{3}$ vs. ionic strength for simulated HA (a) and FA (b) water treatment

Table 2 presents the floc $\mathrm{S}_{f}, \mathrm{R}_{f}$ and $\mathrm{D}_{f}$ under different ionic strength conditions for both HA and FA simulated water treatments. The increase in ionic strength led to an increase in floc $\mathrm{S}_{f}$ to varying degrees. Floc $\mathrm{R}_{f}$ varied from approximately $19.0 \%$ to $25.7 \%$, with the exception that $\mathrm{R}_{f}$ significantly decreased to $6.7 \%$ under the ionic strength of $0.4 \mathrm{~mol} / \mathrm{L}$ in the case of FA simulated water treatment. Moreover, floc compactness was enhanced by increasing the ionic strength of the water. This indicates that $\mathrm{TiCl}_{4}$ is able to produce more dense flocs under certain ionic strength conditions, which is convenient for both HA and FA removal. This may be one reason for the increasing coagulation performance with increasing ionic strength (Fig. 2). However, too high ionic strength causes the decrease in the degree of floc compactness. In the case of the HA simulated water treatment, the floc $\mathrm{D}_{f}$ before breakage increased from 2.46 to 2.83 at ionic strength of $0.05 \mathrm{~mol} / \mathrm{L}$, but decreased to 2.37 at high ionic strength of $0.4 \mathrm{~mol} / \mathrm{L}$.

Table 2 The effect of ionic strength on floc $\mathrm{S}_{f}, \mathrm{R}_{f}$ and $\mathrm{D}_{f}$ for both HA and FA simulated water treatment

\subsection{Membrane filtration to assess membrane fouling}

In this section, the effect of total hardness and ionic strength on membrane fouling using $\mathrm{TiCl}_{4}$ as the coagulant during a C-UF hybrid process was investigated. The 
treated water without sedimentation was added to the magnetically stirred batch cell containing the UF membrane. Flux declines in the UF experiments were used as an indicator to assess the membrane fouling potential of the coagulated effluent.

The normalized membrane permeate fluxes of coagulated effluents were investigated under different total hardness and ionic strength conditions, and the results are presented in Figs. 7 and 8, respectively. The UF performance of filtering raw water under different total hardness and ionic strength conditions was also measured for comparison. Addition of a coagulant prior to the membrane filtration has been suggested as an effective way of reducing membrane fouling (Carroll et al., 2000; Lee et al., 2000). As expected, the pre-coagulation with $\mathrm{TiCl}_{4}$ significantly improves the permeate fluxes as shown in Figs. 7 and 8. In all cases, the fluxes first decreased dramatically with increasing ultrafiltration time, followed by an inconspicuous decline to a relatively steady state. The decrease in membrane permeability is attributed to the floc cake layer that accumulated on UF membrane. Previous studies also reported a close coupling between floc properties and membrane permeability. Both total hardness and ionic strength have a significant influence on membrane permeate flux, resulting in the variation of fluxes under various total hardness and ionic strength conditions. This will be discussed in detail in the following section.

\subsubsection{The effect of total hardness on membrane filtration}

The increase in total hardness reduced the severity of the flux decline of raw water, irrespective of HA or FA simulated water treatment, while the effect of total hardness on the membrane permeate flux of coagulated effluents varied depending on NOM characteristics and floc characteristics (Judd and Hillis 2001, Kimura et al. 2008), as shown in Fig. 7.

Fig. 7 The effect of total hardness on the flux of raw water and flocculated effluent water for simulated HA (a) and FA (b) water treatment ( $\mathrm{TiCl}_{4}$ dose of 10 mg-Ti/L for HA simulated water treatment, and $20 \mathrm{mg}-\mathrm{Ti} / \mathrm{L}$ for FA simulated water treatment)

In the case of HA simulated water treatment (Fig. 7(a)), a significant increase in membrane permeate flux was observed as the total hardness increased to 40 and 200 $\mathrm{mg} / \mathrm{L} \mathrm{CaCO}_{3}$, which could be ascribed to the improvement in floc size (Fig. 4(a)). Large aggregates facilitate suspension permeation, while small aggregates remaining in the coagulated effluent may impede the permeation of suspension (Xu et al. 2011). The decrease in $\mathrm{D}_{f}$ after breakage (Table 1 ) also led to an increase in membrane permeate flux, since the loosely structured aggregates with lower $\mathrm{D}_{f}$ lead to a lower level of resistance to ultrafiltration and thus are beneficial for membrane permeability (Wang et al. 2008). 
In the case of FA simulated water treatment (Fig. 7(b)), the membrane permeate flux was comparable to the total hardness of 0 and $200 \mathrm{mg} / \mathrm{L} \mathrm{CaCO}_{3}$, while the severity of flux decline was enhanced by the total hardness of $40 \mathrm{mg} / \mathrm{L} \mathrm{CaCO}_{3}$. Floc strength has previously been proved to be an important factor influencing membrane permeate flux (Xu et al. 2011), since flocs with larger $S_{f}$ are not likely to be destroyed, and leave fewer aggregate fractions in the feed water, thus facilitating suspension permeation. As shown in Table 1, floc $\mathrm{S}_{f}$ decreased from around $41.0 \%$ to $38.3 \%$ and $36.0 \%$, respectively when total hardness increased to 40 and $200 \mathrm{mg} / \mathrm{L} \mathrm{CaCO}_{3}$. However, the severity of permeate flux was not consistent with the sequence of floc strength, which indicates that floc strength is not the dominant factor influencing the membrane permeate flux in this case. Little variation in floc size under different total hardness conditions (Fig. 4(b)) indicates that the membrane permeate flux is barely affected by floc size. Floc $\mathrm{D}_{f}$ after breakage increased from 2.74 to 2.78 when the total hardness increased from 0 to $40 \mathrm{mg} / \mathrm{L} \mathrm{CaCO}_{3}$, but decreased to 2.74 again at a total hardness of $200 \mathrm{mg} / \mathrm{L} \mathrm{CaCO}_{3}$. This trend corresponds to the severity of membrane permeate flux, which indicates that floc $\mathrm{D}_{f}$ may actually be responsible for the variation in membrane permeability in this case.

\subsubsection{The effect of ionic strength on membrane filtration}

According to Fig. 8, the membrane permeate fluxes for both raw HA and FA simulated water were slightly influenced by ionic strength. For coagulated effluent, the responses of membrane permeate flux to ionic strength varied significantly for HA and FA simulated water treatment.

Fig. 8 The effect of ionic strength on the flux of raw water and flocculated effluent water for simulated HA (a) and FA (b) water treatment $\left(\mathrm{TiCl}_{4}\right.$ dose of 10 $\mathrm{mg}-\mathrm{Ti} / \mathrm{L}$ for HA simulated water treatment, and $20 \mathrm{mg}-\mathrm{Ti} / \mathrm{L}$ for FA simulated water treatment)

In the case of HA simulated water treatment (Fig. 8(a)), the membrane permeability increased with increasing ionic strength. The flux improvement at ionic strength of $0.4 \mathrm{~mol} / \mathrm{L}$ was the most effective, with the largest eventual permeate flux, which can be attributed to the improvement in floc size (Fig. 6(a)) and floc strength (Table 2), and the decrease in floc $\mathrm{D}_{f}$ (Table 2). As previously noted, the flocs with large size, high strength and loosely bounded structure favour membrane permeability. A moderate flux was observed at ionic strength of $0.05 \mathrm{~mol} / \mathrm{L}$, where both the floc size and strength were improved, but the flocs had more compact structure with higher $\mathrm{D}_{f}$ than those at ionic strength of $0 \mathrm{~mol} / \mathrm{L}$. Thus, the variation in membrane permeate flux depends on the combined effect of different floc characteristics.

In the case of FA simulated water treatment (Fig. 8(b)), the fluxes were less sensitive to the increasing ionic strength than those in the HA simulated water treatment. This indicates that NOM characteristics significantly influence membrane permeability 
besides floc properties. As mentioned above, the flocs with large size and high strength facilitate the membrane permeation, which therefore reduce the membrane fouling. Whilst the improvement in the degree of floc compactness deteriorates the membrane permeability as previously noted (Wang et al., 2008). The floc size and floc strength were enhanced by increasing ionic strength from 0 to $0.05 \mathrm{~mol} / \mathrm{L}$, while floc $\mathrm{D}_{f}$ increased as shown in Table 2. However, little improvement in the membrane permeability was observed, since the positive effect of floc size and strength on membrane permeability was offset by the increase in floc compactness, which resulted in the deterioration of membrane permeability. As presented in Fig. 8(b), the membrane permeate flux was not obviously influenced even the ionic strength further increased to $0.4 \mathrm{~mol} / \mathrm{L}$.

\section{Conclusions}

In this study, the effect of total hardness and ionic strength on coagulation performance and floc characteristics of $\mathrm{TiCl}_{4}$ was investigated for both $\mathrm{HA}$ and $\mathrm{FA}$ simulated water treatments. Membrane fouling under different total hardness and ionic strength conditions was also examined during the coagulation-ultrafiltration hybrid process. The main conclusions are as follows.

1. For both HA and FA simulated water treatments, the increase in total hardness and ionic strength enhances both particulate and organic matter removal. The main coagulation mechanism was sweep flocculation.

2. Both floc size and growth rate were improved by increasing total hardness in the case of HA simulated water treatment, while they were independent of the total hardness in the case of FA simulated water treatment. Floc strength showed an irregular increase or decrease depending the on $\mathrm{TiCl}_{4}$ dose, while floc recoverability and floc compactness were enhanced by increasing total hardness. Similarly, the floc characteristics of $\mathrm{TiCl}_{4}$ were improved by increasing ionic strength.

3. During the C-UF hybrid process, the pre-coagulation with $\mathrm{TiCl}_{4}$ significantly improved the permeate fluxes, and membrane permeability was significantly influenced by total hardness and ionic strength. In the case of HA simulated water treatment, the increase in total hardness and ionic strength improved the membrane permeate flux, while it was barely influenced by either total hardness or ionic strength in the case of FA simulated water treatment.

\section{Acknowledgements}

This work was supported by grants from the Chinese National Natural Science Foundation (No. 51278283), Australia Research Council Discovery Projects (ARC DP), and the Shanghai Tongji Gao Tingyao Environmental Science \& Technology Development Foundation (STGEF), and by a scholarship from the China Scholarship Council. 


\section{References}

Boller, M., Blaser, S., 1998. Particles under stress. Water Sci. Technol. 37, 9-29.

Cao, B., Gao, B., Liu, X., Wang, M., Yang, Z., Yue, Q., 2011. The impact of pH on floc structure characteristic of polyferric chloride in a low DOC and high alkalinity surface water treatment. Water Res. 45, 6181-6188.

Carroll, T., King, S., Gray, S., Bolto, B.A., Booker, N., 2000. The fouling of microfiltration membranes by NOM after coagulation treatment. Water Res. 34, 2861-2868.

Duan, J., Gregory, J., 2003. Coagulation by hydrolysing metal salts. Adv. Colloid Interface Sci. 100, 475-502.

Gregory, J., 1998. The role of floc density in solid-liquid separation. Filtr. Sep. 35, 367-366.

Guigui, C., Rouch, J., Durand-Bourlier, L., Bonnelye, V., Aptel, P., 2002. Impact of coagulation conditions on the in-line coagulation/UF process for drinking water production. Desalination 147, 95-100.

Hankins, N.P., Lu, N., Hilal, N., 2006. Enhanced removal of heavy metal ions bound to humic acid by polyelectrolyte flocculation. Sep. Purif. Technol. 51, 48-56.

Hoffmann, M.R., Yost, E.C., Eisenreich, S.J., Maier, W.J., 1981. Characterization of soluble and colloidal phase metal complexes in river water by ultrafiltration. A mass-balance approach. Environ. Sci. Technol. 15, 655-661.

Hoffmann, M.R., Martin, S.T., Choi, W., Bahnemann, D.W., 1995. Environmental applications of semiconductor photocatalysis. Chem. Rev. 95, 69-96.

Hopkins, D.C., Ducoste, J.J., 2003. Characterizing flocculation under heterogeneous turbulence. J. Colloid Interface Sci. 264, 184-194.

Hu, C., Liu, H., Qu, J., Wang, D., Ru, J., 2006. Coagulation behavior of aluminum salts in eutrophic water: significance of $\mathrm{Al}_{13}$ species and $\mathrm{pH}$ control. Environ. Sci. Technol. 40, 325-331.

Jarvis, P., Jefferson, B., Parsons, S.A., 2005. Breakage, regrowth, and fractal nature of natural organic matter flocs. Environ. Sci. Technol. 39, 2307-2314.

Jucker, C., Clark, M.M., 1994. Adsorption of aquatic humic substances on hydrophobic ultrafiltration membranes. Journal of membrane science 97, 37-52.

Judd, S., Hillis, P., 2001. Optimisation of combined coagulation and microfiltration for water treatment. Water Res. 35, 2895-2904.

Kabsch-Korbutowicz, M., 2005. Application of ultrafiltration integrated with coagulation for improved NOM removal. Desalination 174, 13-22.

Kane, M., 1987. Conventry Area Sewage Sludge Disoposal Scheme: Development of Strategy and Early Operating Experiences. Water Environ. J. 1, 305-314.

Kimura, K., Maeda, T., Yamamura, H., Watanabe, Y., 2008. Irreversible membrane fouling in microfiltration membranes filtering coagulated surface water. J. Membr. Sci. 320, 356-362.

Lee, J.-D., Lee, S.-H., Jo, M.-H., Park, P.-K., Lee, C.-H., Kwak, J.-W., 2000. Effect of coagulation conditions on membrane filtration characteristics in 
coagulation-microfiltration process for water treatment. Environ. Sci. Technol. 34, 3780-3788.

Lee, B., Kim, S., Shon, H., Vigneswaran, S., Kim, S., Cho, J., Kim, I.S., Choi, K., Kim, J., Park, H., 2009. Aquatic toxicity evaluation of $\mathrm{TiO}_{2}$ nanoparticle produced from sludge of $\mathrm{TiCl}_{4}$ flocculation of wastewater and seawater. J. Nanopart. Res. 11, 2087-2096.

Lin, J.L., Huang, C., Chin, C.J.M., Pan, J.R., 2008. Coagulation dynamics of fractal flocs induced by enmeshment and electrostatic patch mechanisms. Water Res. 42, 4457-4466.

McCurdy, K., Carlson, K., Gregory, D., 2004. Floc morphology and cyclic shearing recovery: comparison of alum and polyaluminum chloride coagulants. Water Res. 38, 486-494.

Nassar, A.M., Smith, M., Afifi, S., 2009. Palestinian experience with sewage sludge utilizing reed beds. Water Environ. J. 23, 75-82.

Obee, T.N., Brown, R.T., 1995. $\mathrm{TiO}_{2}$ photocatalysis for indoor air applications: effects of humidity and trace contaminant levels on the oxidation rates of formaldehyde, toluene, and 1, 3-butadiene. Environ. Sci. Technol. 29, 1223-1231.

Oh, J.-I., 2005. Influence of streaming potential on flux decline of microfiltration with in-line rapid pre-coagulation process for drinking water production. J. Membr. Sci. 254, 39-47.

Okour, Y., Shon, H., El Saliby, I., Naidu, R., Kim, J. and Kim, J.-H. (2010) Preparation and characterisation of titanium dioxide $\left(\mathrm{TiO}_{2}\right)$ and thiourea-doped titanate nanotubes prepared from wastewater flocculated sludge. Bioresour. Technol. 101(5), 1453-1458.

Park, P.-k., Lee, C.-h., Choi, S.-J., Choo, K.-H., Kim, S.-H., Yoon, C.-H., 2002. Effect of the removal of DOMs on the performance of a coagulation-UF membrane system for drinking water production. Desalination 145, 237-245.

Rieker, T.P., Hindermann-Bischoff, M., Ehrburger-Dolle, F., 2000. Small-angle X-ray scattering study of the morphology of carbon black mass fractal aggregates in polymeric composites. Langmuir 16, 5588-5592.

Selomulya, C., Amal, R., Bushell, G., Waite, T.D., 2001. Evidence of shear rate dependence on restructuring and breakup of latex aggregates. J. Colloid Interface Sci. 236, 67-77.

Senesi, N., 1990. Molecular and quantitative aspects of the chemistry of fulvic acid and its interactions with metal ions and organic chemicals: Part I. The electron spin resonance approach. Analytica Chimica Acta 232, 51-75.

Shon, H., Vigneswaran, S., Kandasamy, J., Zareie, M., Kim, J., Cho, D., Kim, J.H., 2009. Preparation and Characterization of Titanium Dioxide $\left(\mathrm{TiO}_{2}\right)$ from Sludge produced by $\mathrm{TiCl}_{4}$ Flocculation with $\mathrm{FeCl}_{3}, \mathrm{Al}_{2}\left(\mathrm{SO}_{4}\right)_{3}$ and $\mathrm{Ca}(\mathrm{OH})_{2}$ Coagulant Aids in Wastewater. Sep. Sci. Technol. 44, 1525-1543.

Shon, H., Vigneswaran, S., Kim, I.S., Cho, J., Kim, G., Kim, J., Kim, J.H., 2007. Preparation of Titanium Dioxide $\left(\mathrm{TiO}_{2}\right)$ from Sludge Produced by Titanium 
Tetrachloride $\left(\mathrm{TiCl}_{4}\right)$ Flocculation of Wastewater. Environ. Sci. Technol. 41, 1372-1377.

Tipping, E., 1994. WHAMC—A chemical equilibrium model and computer code for waters, sediments, and soils incorporating a discrete site/electrostatic model of ion-binding by humic substances. Compu. Geosci. 20, 973-1023.

Tuncay, M., Christian, S.D., Tucker, E.E., Taylor, R.W., Scamehorn, J.F., 1994. Ligand-modified polyelectrolyte-enhanced ultrafiltration with electrostatic attachment of ligands. 1. Removal of $\mathrm{Cu}$ (II) and $\mathrm{Pb}$ (II) with expulsion of $\mathrm{Ca}$ (II). Langmuir 10, 4688-4692.

Wang, J., Guan, J., Santiwong, S., Waite, T.D., 2008. Characterization of floc size and structure under different monomer and polymer coagulants on microfiltration membrane fouling. J. Membr. Sci. 321, 132-138.

Wang, Y., Gao, B.-Y., Xu, X.-M., Xu, W.-Y., 2010. The effect of total hardness and ionic strength on the coagulation performance and kinetics of aluminum salts to remove humic acid. Chem. Eng. J. 160, 150-156.

Wang, Y., Mao, R., Wang, Q., Yang, Z., Gao, B., Zhao, Y., 2012. Fulvic acid removal performance and control of disinfection by-product formation potential in coagulation-ultrafiltration process. Desalination 302, 55-64.

Wei, J., Gao, B., Yue, Q., Wang, Y., Li, W., Zhu, X., 2009. Comparison of coagulation behavior and floc structure characteristic of different polyferric-cationic polymer dual-coagulants in humic acid solution. Water Res. 43, 724-732.

Xiao, F., Yi, P., Pan, X.-R., Zhang, B.-J., Lee, C., 2010. Comparative study of the effects of experimental variables on growth rates of aluminum and iron hydroxide flocs during coagulation and their structural characteristics. Desalination 250, 902-907.

Xu, J., Gong, P., Qin, X., 2009. Research on hydrolysis of $\mathrm{TiCl}_{4}$ characteristic. Petrochem. Ind. Appl. 28, 13-15.

Xu, S.J., 2002. Inorganic Chemistry, third edi., People’s Medical Publishing House, Beijing.

Xu, W., Gao, B., Mao, R., Yue, Q., 2011. Influence of floc size and structure on membrane fouling in coagulation-ultrafiltration hybrid process-The role of $\mathrm{Al}_{13}$ species. J. Hazard. Mater. 193, 249-256.

Yang, Z.L., Gao, B.Y., Yue, Q.Y., Wang, Y., 2010. Effect of pH on the coagulation performance of Al-based coagulants and residual aluminum speciation during the treatment of humic acid-kaolin synthetic water. J. Hazard. Mater. 178, 596-603.

Yu, W., Li, G., Xu, Y., Yang, X., 2009. Breakage and re-growth of flocs formed by alum and PACl. Powder Technol. 189, 439-443.

Yukselen, M.A., Gregory, J., 2004. The reversibility of floc breakage. Int. J. Miner. Process 73, 251-259.

Zhao, Y., Gao, B., Cao, B., Yang, Z., Yue, Q., Shon, H., Kim, J.H., 2011a. Comparison of coagulation behavior and floc characteristics of titanium tetrachloride $\left(\mathrm{TiCl}_{4}\right)$ and polyaluminum chloride $(\mathrm{PACl})$ with surface water treatment. Chem. Eng. J. 166, 544-550. 
Zhao, Y., Gao, B., Shon, H., Cao, B., Kim, J.H., 2011b. Coagulation characteristics of titanium (Ti) salt coagulant compared with aluminum (Al) and iron (Fe) salts. J. Hazard. Mater. 185, 1536-1542.

Zhao, Y., Gao, B., Shon, H., Kim, J.-H., Yue, Q., 2011c. Effect of shear force, solution $\mathrm{pH}$ and breakage period on characteristics of flocs formed by Titanium tetrachloride $\left(\mathrm{TiCl}_{4}\right)$ and Polyaluminum chloride (PACl) with surface water treatment. J. Hazard. Mater. 187, 495-501.

Zhao, Y., Gao, B., Shon, H., Kim, J.H., Yue, Q., Wang, Y., 2011d. Floc characteristics of titanium tetrachloride $\left(\mathrm{TiCl}_{4}\right)$ compared with aluminum and iron salts in humic acid-kaolin synthetic water treatment. Sep. Purif. Technol. 81, 332-338.

Zhao, Y., Gao, B., Shon, H., Wang, Y., Kim, J.H., Yue, Q., Bo, X., 2012. Anionic polymer compound bioflocculant as a coagulant aid with aluminum sulfate and titanium tetrachloride. Bioresour. Technol. 108, 45-54.

Zularisam, A., Ismail, A., Salim, R., 2006. Behaviours of natural organic matter in membrane filtration for surface water treatment-a review. Desalination 194, 211-231. 
Figure list

Fig. 1 The effect of total hardness on coagulation performance for simulated HA (a) and FA (b) water treatment

Fig. 2 The effect of ionic strength on coagulation performance for simulated HA (a) and FA (b) water treatment

Fig. 3 The kinetic floc growth, breakage and regrowth profiles under different total hardness conditions for simulated HA (a) and FA (b) water treatment

Fig. 4 Variation of floc growth rate and floc size $d_{1}, d_{2}$ and $d_{3}$ vs. total hardness for simulated HA (a) and FA (b) water treatment

Fig. 5 The kinetic floc growth, breakage and regrowth profiles under different ionic strength conditions for simulated HA (a) and FA (b) water treatment

Fig. 6 Variation of floc growth rate and floc size $d_{1}, d_{2}$ and $d_{3}$ vs. ionic strength for simulated HA (a) and FA (b) water treatment

Fig. 7 The effect of total hardness on the flux of raw water and flocculated effluent water for simulated HA (a) and FA (b) water treatment $\left(\mathrm{TiCl}_{4}\right.$ dose of 10 $\mathrm{mg}-\mathrm{Ti} / \mathrm{L}$ for HA simulated water treatment, and $20 \mathrm{mg}-\mathrm{Ti} / \mathrm{L}$ for FA simulated water treatment)

Fig. 8 The effect of ionic strength on the flux of raw water and flocculated effluent water for simulated HA (a) and FA (b) water treatment $\left(\mathrm{TiCl}_{4}\right.$ dose of 10 $\mathrm{mg}-\mathrm{Ti} / \mathrm{L}$ for HA simulated water treatment, and $20 \mathrm{mg}-\mathrm{Ti} / \mathrm{L}$ for FA simulated water treatment) 
(a)

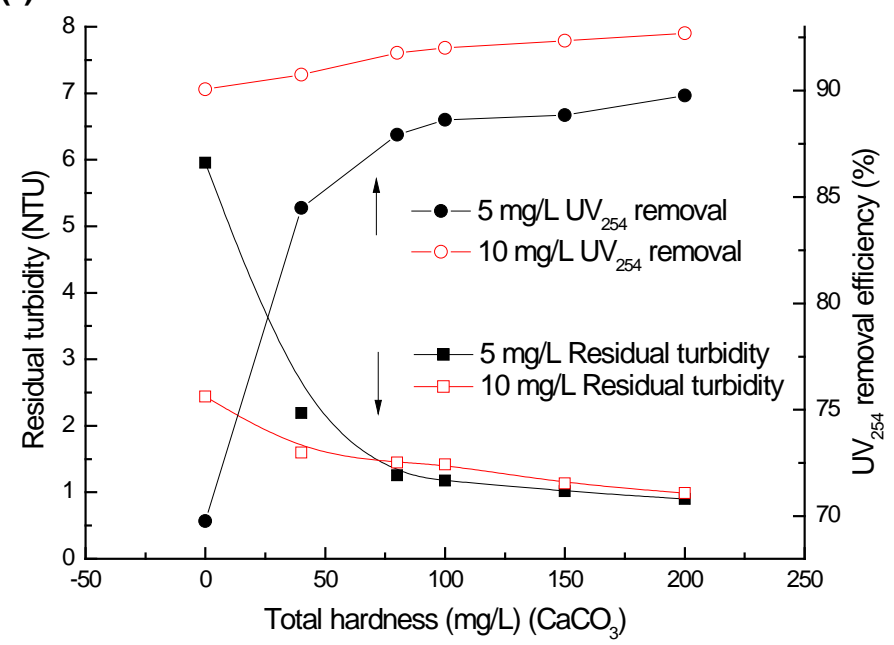

(b)

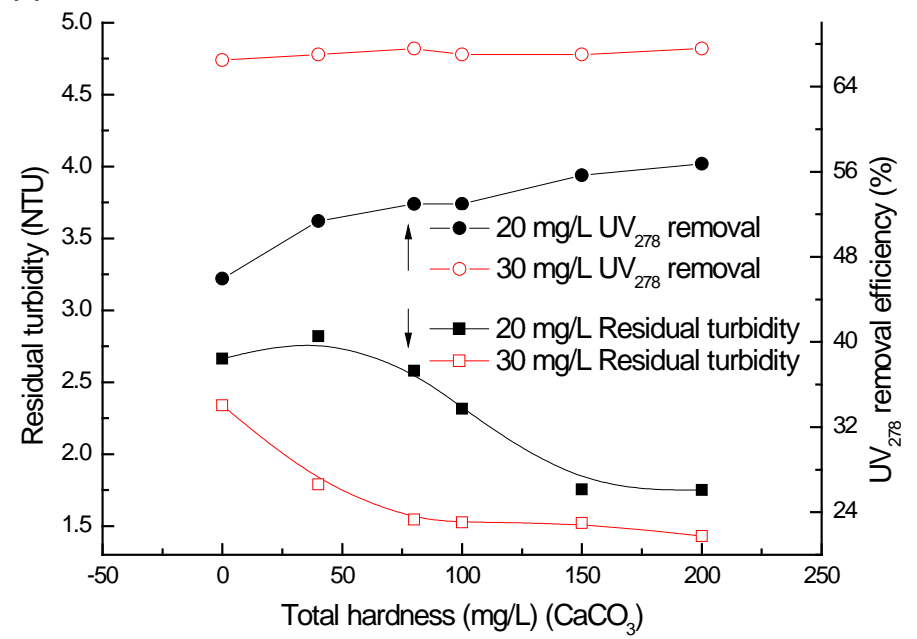

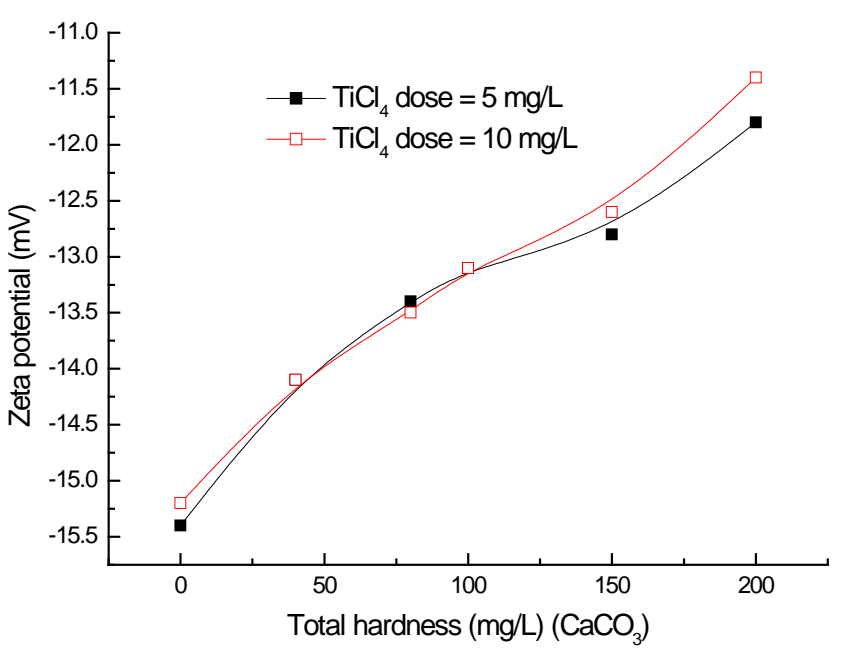

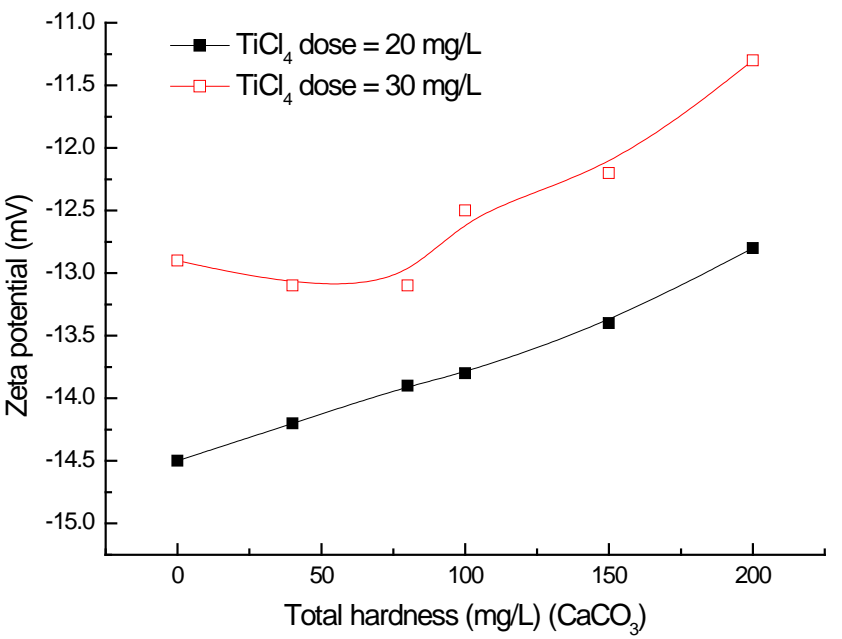


Fig. 1 The effect of total hardness on coagulation performance for simulated HA (a) and FA (b) water treatment 

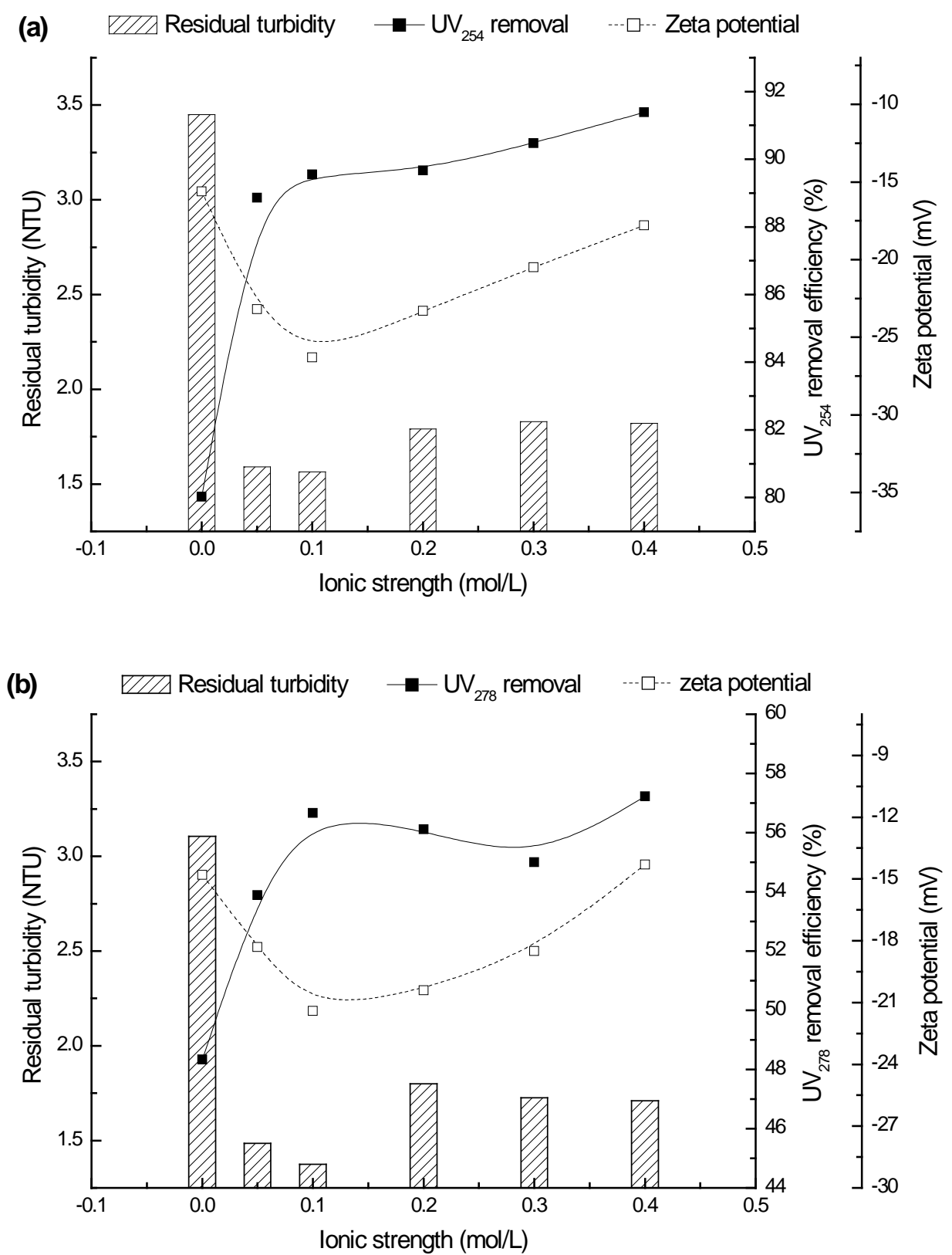
Fig. 2 The effect of ionic strength on coagulation performance for simulated HA (a) and FA (b) water treatment 

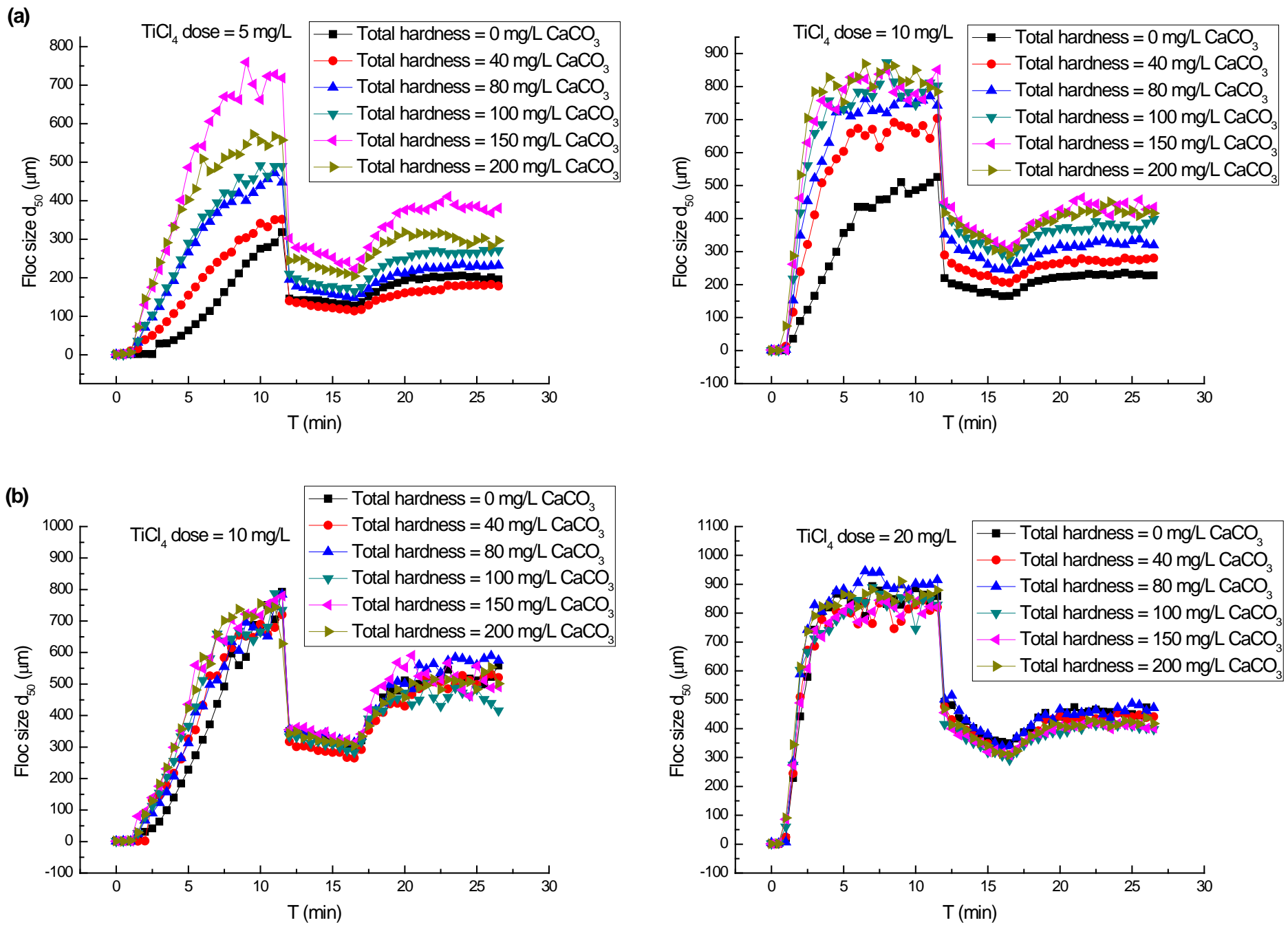
Fig. 3 The kinetic floc growth, breakage and regrowth profiles under different total hardness conditions for simulated HA (a) and FA (b) water treatment 
(a)

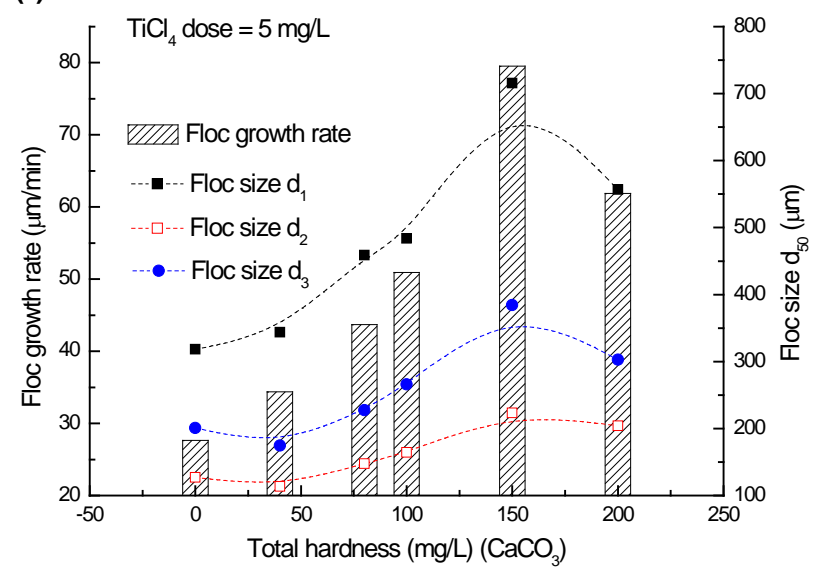

(b)

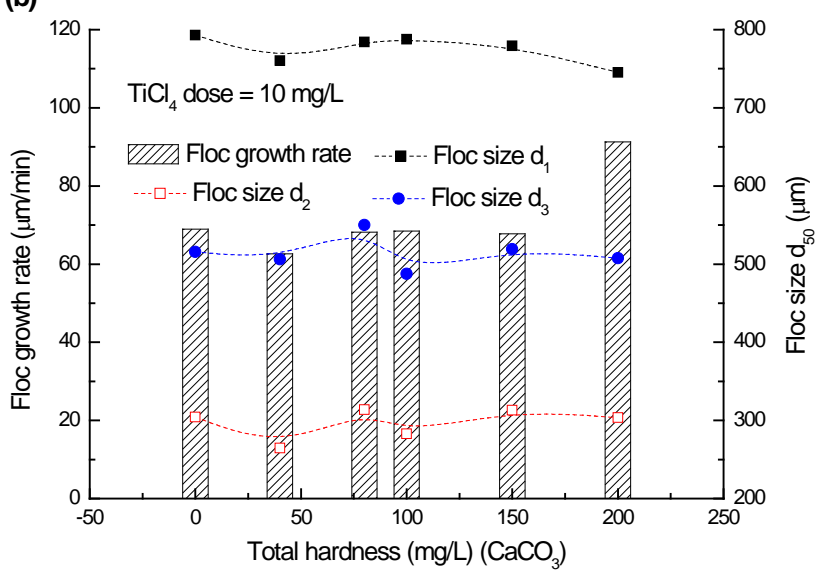

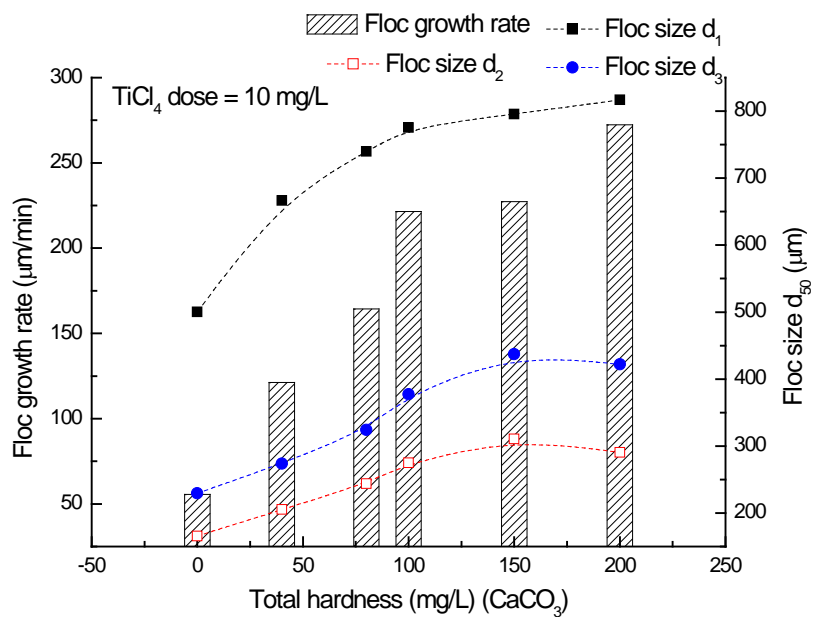

$\mathrm{TiCl}_{4}$ dose $=20 \mathrm{mg} / \mathrm{L}$

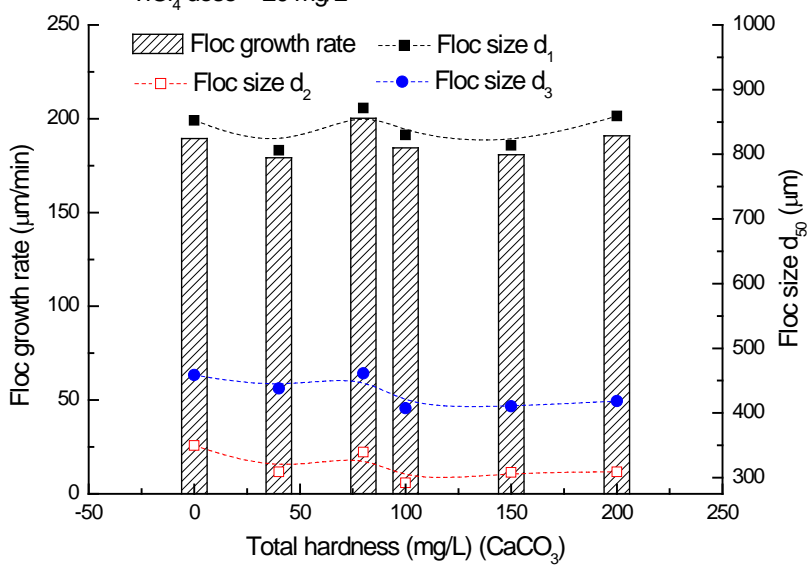


Fig. 4 Variation of floc growth rate and floc size $d_{1}, d_{2}$ and $d_{3}$ vs. total hardness for simulated HA (a) and FA (b) water treatment 

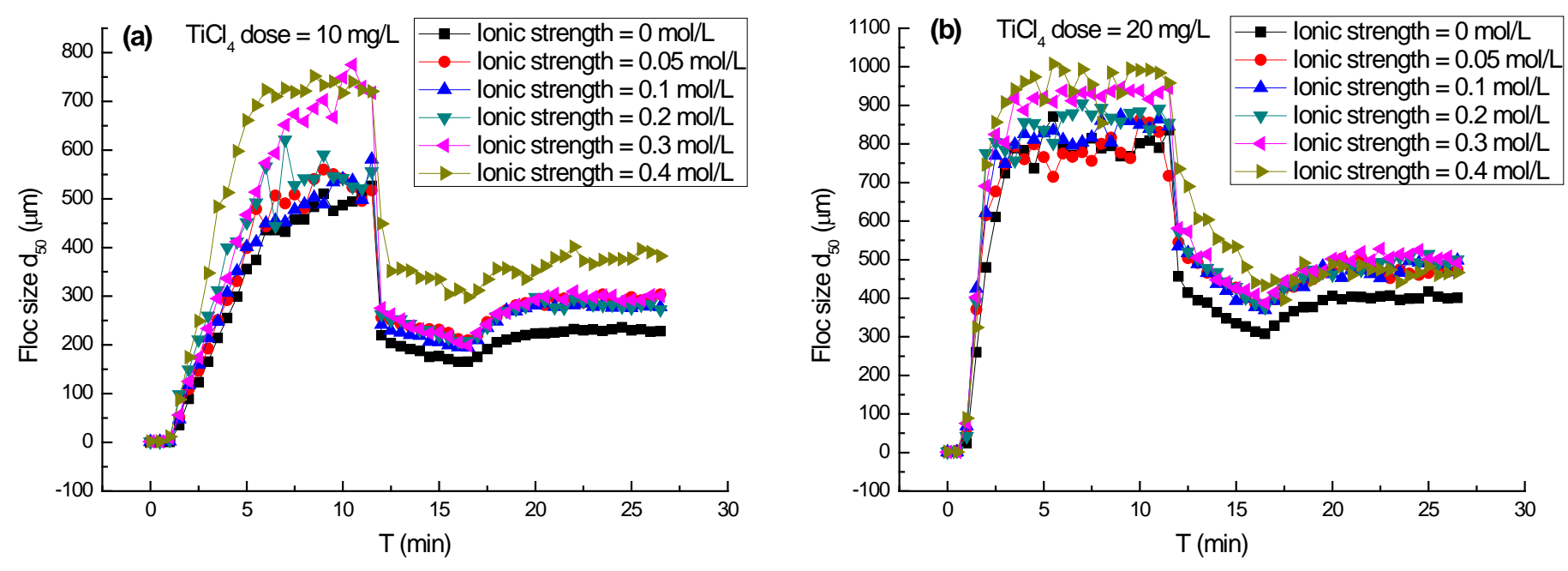

Fig. 5 The kinetic floc growth, breakage and regrowth profiles under different ionic strength conditions for simulated HA (a) and FA (b) water treatment 

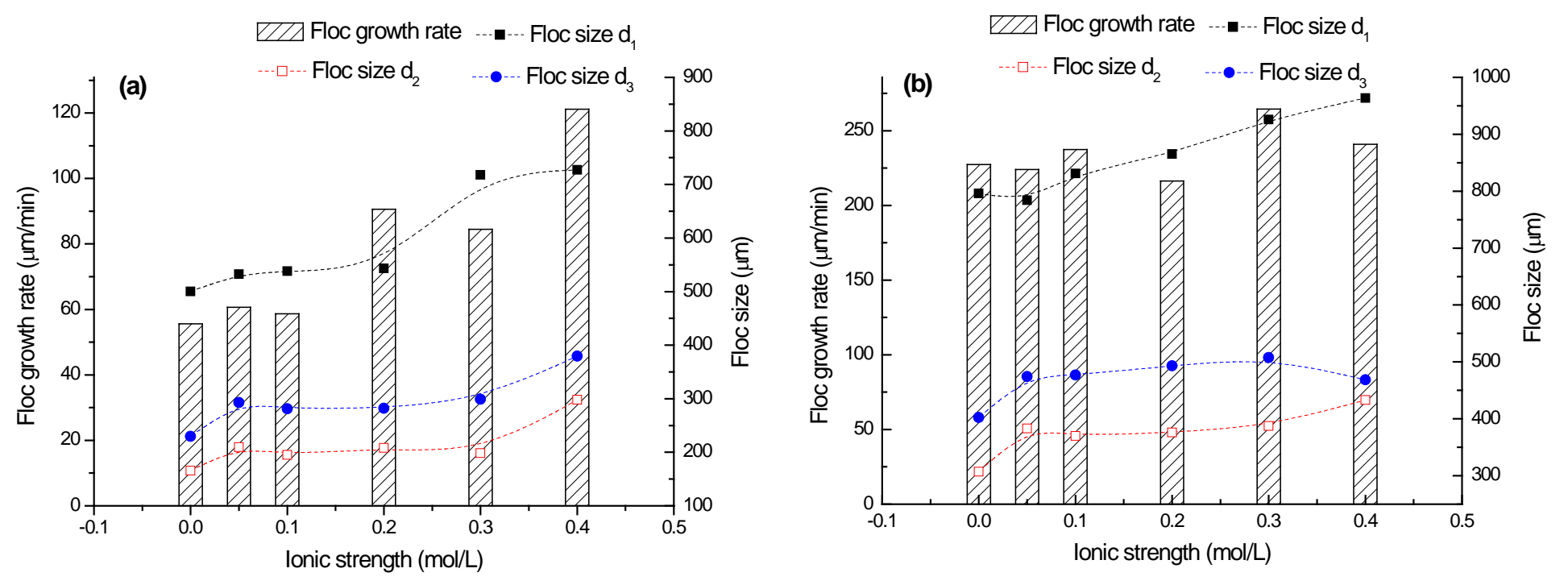

Fig. 6 Variation of floc growth rate and floc size $d_{1}, d_{2}$ and $d_{3}$ vs. ionic strength for simulated HA (a) and FA (b) water treatment 

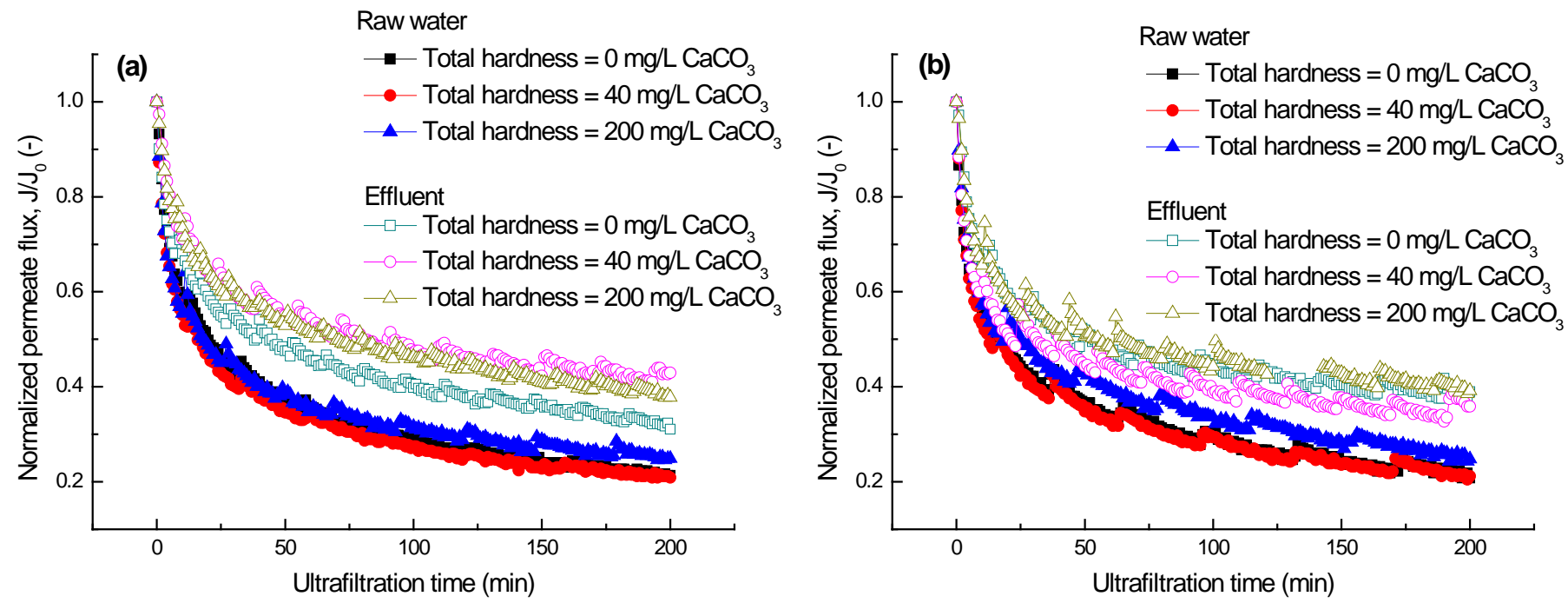

Fig. 7 The effect of total hardness on the flux of raw water and flocculated effluent water for simulated HA (a) and FA (b) water treatment ( $\mathrm{TiCl}_{4}$ dose of $10 \mathrm{mg}$-Ti/L for HA simulated water treatment, and $20 \mathrm{mg}-\mathrm{Ti} / \mathrm{L}$ for FA simulated water treatment) 
Table list

Table 1 The effect of total hardness on floc $S_{f}, R_{f}$ and $D_{f}$ for both HA and FA simulated water treatment

Table 2 The effect of ionic strength on floc $S_{f}, R_{f}$ and $D_{f}$ for both HA and FA simulated water treatment 
Table 1 The effect of total hardness on floc $S_{f}, R_{f}$ and $D_{f}$ for both HA and FA simulated water treatment

\begin{tabular}{|c|c|c|c|c|c|c|c|c|}
\hline & & & \multicolumn{6}{|c|}{ Total hardness $(\mathrm{mg} / \mathrm{L})\left(\mathrm{CaCO}_{3}\right)$} \\
\hline & & & 0 & 40 & 80 & 100 & 150 & 200 \\
\hline \multirow{3}{*}{$\begin{array}{c}\text { HA } \\
\text { simulated } \\
\text { water }\end{array}$} & $\mathrm{TiCl}_{4}$ & $\mathrm{~S}_{f}$ & 39.93 & 32.98 & 32.16 & 33.97 & 31.19 & 36.68 \\
\hline & dose $=$ & $\mathrm{R}_{f}$ & 38.53 & 26.53 & 25.62 & 31.80 & 32.69 & 27.93 \\
\hline & $5 \mathrm{mg} / \mathrm{L}$ & $\mathrm{D}^{\mathrm{a}}$ & 2.29 & 2.47 & 2.46 & 2.46 & 2.43 & 2.53 \\
\hline & & & & 34 & & & & \\
\hline
\end{tabular}




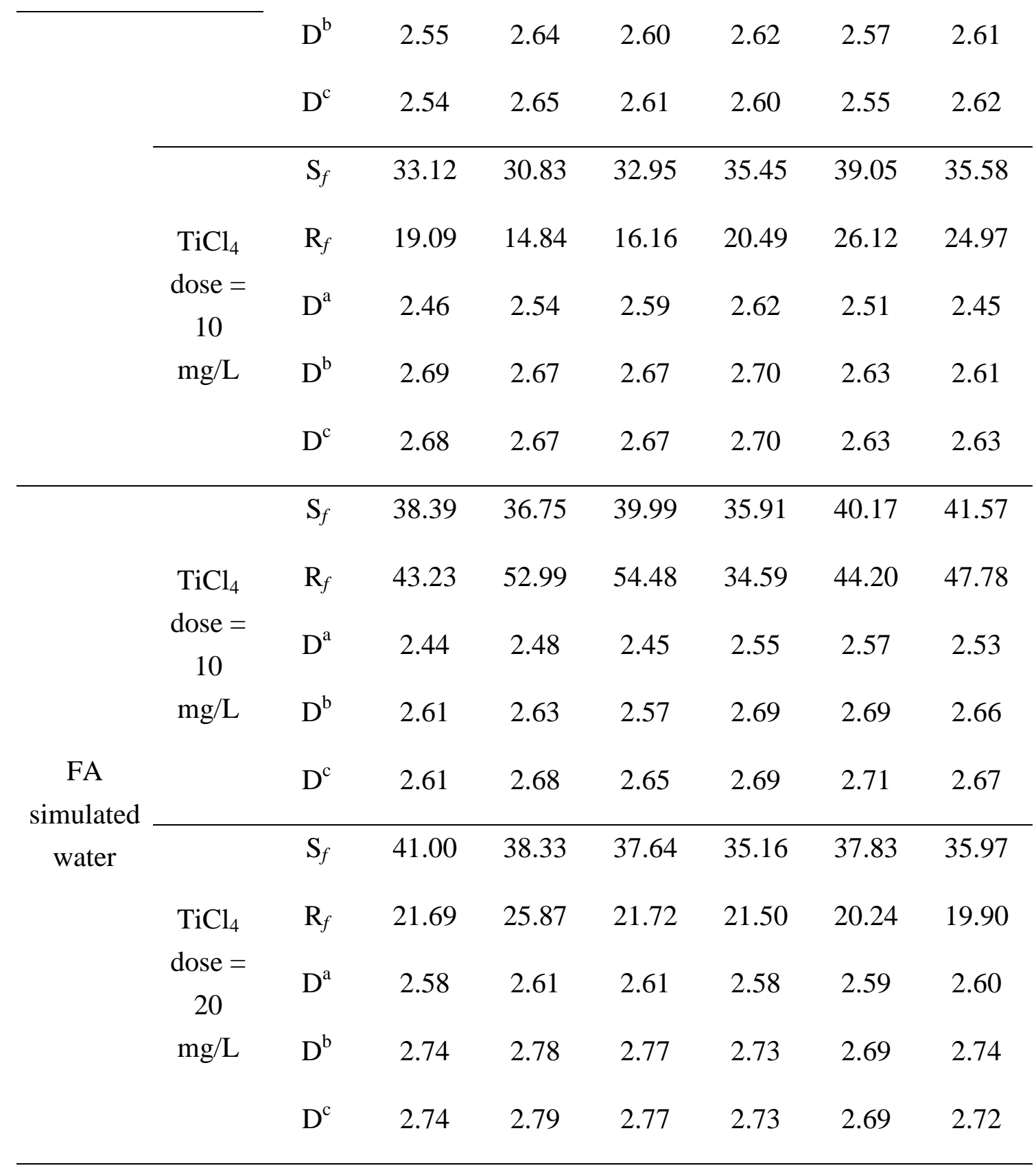

$* \mathrm{D}^{\mathrm{a}}$ : $\mathrm{D}_{f}$ before floc breakage; $\mathrm{D}^{\mathrm{b}}: \mathrm{D}_{f}$ after floc breakage; $\mathrm{D}^{\mathrm{c}}: \mathrm{D}_{f}$ after floc regrowth 
Table 2 The effect of ionic strength on floc $S_{f}, R_{f}$ and $D_{f}$ for both HA and FA simulated water treatment

\begin{tabular}{|c|c|c|c|c|c|c|c|}
\hline & & \multicolumn{6}{|c|}{ Ionic strength (mol/L) } \\
\hline & & 0 & 0.05 & 0.1 & 0.2 & 0.3 & 0.4 \\
\hline \multirow{5}{*}{$\begin{array}{c}\text { HA } \\
\text { simulated } \\
\text { water }\end{array}$} & $\mathrm{S}_{f}$ & 33.12 & 39.37 & 36.27 & 38.28 & 37.63 & 40.99 \\
\hline & $\mathrm{R}_{f}$ & 19.09 & 25.72 & 25.04 & 22.11 & 19.32 & 19.00 \\
\hline & $\mathrm{D}^{\mathrm{a}}$ & 2.46 & 2.83 & 2.55 & 2.61 & 2.45 & 2.37 \\
\hline & $\mathrm{D}^{\mathrm{b}}$ & 2.69 & 2.97 & 2.70 & 2.72 & 2.60 & 2.56 \\
\hline & $D^{c}$ & 2.68 & 2.95 & 2.70 & 2.72 & 2.51 & 2.52 \\
\hline \multirow{5}{*}{$\begin{array}{c}\text { FA } \\
\text { simulated } \\
\text { water }\end{array}$} & $\mathrm{S}_{f}$ & 38.59 & 48.85 & 44.49 & 43.47 & 41.85 & 44.91 \\
\hline & $\mathrm{R}_{f}$ & 19.47 & 22.72 & 23.25 & 23.95 & 22.33 & 6.72 \\
\hline & $\mathrm{D}^{\mathrm{a}}$ & 2.58 & 2.67 & 2.65 & 2.63 & 2.64 & 2.46 \\
\hline & $\mathrm{D}^{\mathrm{b}}$ & 2.74 & 2.81 & 2.80 & 2.78 & 2.79 & 2.70 \\
\hline & $D^{c}$ & 2.74 & 2.82 & 2.80 & 2.79 & 2.80 & 2.68 \\
\hline
\end{tabular}

$* \mathrm{D}^{\mathrm{a}}$ : $\mathrm{D}_{f}$ before floc breakage; $\mathrm{D}^{\mathrm{b}}: \mathrm{D}_{f}$ after floc breakage; $\mathrm{D}^{\mathrm{c}}: \mathrm{D}_{f}$ after floc regrowth 

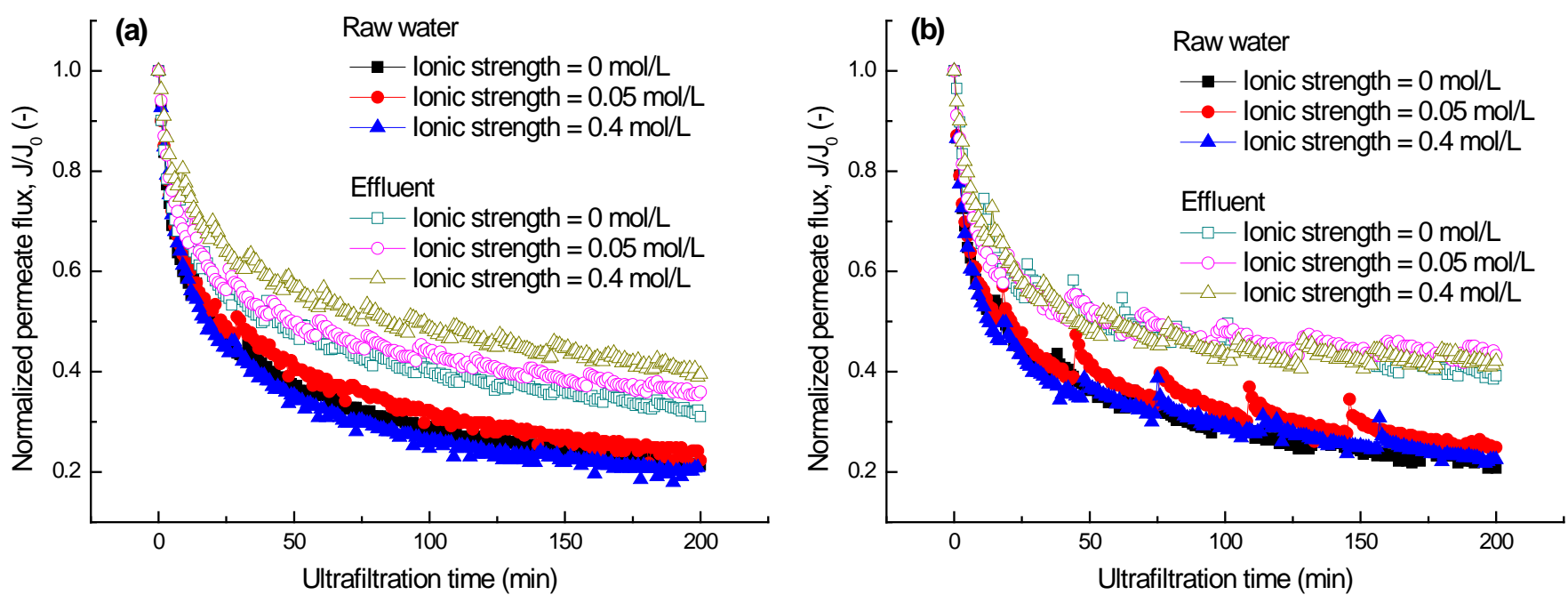

Fig. 8 The effect of ionic strength on the flux of raw water and flocculated effluent water for simulated HA (a) and FA (b) water treatment $\left(\mathrm{TiCl}_{4}\right.$ dose of $10 \mathrm{mg}-\mathrm{Ti} / \mathrm{L}$ for HA simulated water treatment, and $20 \mathrm{mg}-\mathrm{Ti} / \mathrm{L}$ for FA simulated water treatment) 